\title{
Corpo e origami: Um estudo sobre dobras e sua inovação dentro da arte contemporânea
}

\section{Body and origami: a study on innovation of folds in contemporary art}

Samanta Aline Teixeira ${ }^{1}$

Caroline Apolinário Gomes ${ }^{2}$

Luis Carlos Paschoarelli ${ }^{3}$

Milton Koji Nakata Monica Moura 


\section{Resumo}

Esse artigo analisa a arte contemporânea em comunhão com as técnicas criativas do corpo e do origami, gerando o entrelaçamento entre as diferentes artes corporais e a tecnologia a elas aplicada. Em um primeiro momento, é analisado o cenário contemporâneo, as novas tecnologias e os caminhos da sociedade atual. Em um segundo momento, considera-se o comportamento do corpo e do origami inseridos dentro desse novo contexto. Por fim, são analisados alguns projetos que utilizam como principal alicerce a performance corporal e as dobraduras japonesas.

Palavras-chave: corpo, origami, arte, dobras, contemporâneo.

\section{Abstract}

This article analyzes the contemporary art in union with the creative techniques of body and origami, creating connections between different body arts and the technology applied to them. In a first moment, we analyze the contemporary scene, the new technologies and the paths of today's society. In a second moment, it is considered the body's behavior and origami inserted within this new context. Finally, some projects are analyzed using body performance and Japanese folding as main foundation.

Keywords: body, origami, art, folds, contemporary.

ISSN: 2175-2346

1 Mestranda na Pós Graduação em Design, Planejamento de Produto, pela UNESP - Universidade Estadual Paulista "Júlio de Mesquita Filho", Brasil laranjasat@gmail.com

2 Mestranda na Pós Graduação em Design, Planejamento de Produto, pela UNESP - Universidade Estadual Paulista “Júlio de Mesquita Filho”, Brasil caroline.agomes@gmail.com

3 Docente em Design Ergonômico pela Universidade Estadual Paulista "Júlio de Mesquita Filho", Brasil

paschoarelli@faac.unesp.br
4 Professor assistente doutor da Universidade Estadual Paulista Júlio de Mesquita Filho, Brasil milton@faac.unesp.br

5 Professora Assistente Doutora no Departamento de Design, Professora Permanente e Orientadora Credenciada no Programa de Pós Graduação em Design da Faculdade de Arquitetura, Artes e Comunicação - FAAC, Brasil monicamoura@faac.unesp.br 


\section{INTRODUÇÃO}

O momento atual, entendido por contemporâneo, vai além de uma época posterior ao moderno. De fato, engloba singularidades que constituem a atualidade e implicam nas mudanças dos modos de vida e de comportamentos da sociedade como um todo. Encontramos-nos diante de um momento onde se valoriza o processo, a experiência do que acontece no "meio" das coisas, nas passagens, nas miscigenações; e não, necessariamente, no resultado ou produto final.

Diante de diversos projetos multidisciplinares, no presente texto citados e analisados, observa-se que os processos criativos fechados e fixos, pouco a pouco vão se diluindo e abrindo caminho para novas formas de diálogo criativas, muito mais abertas e conectivas. Uma das formas de se pensar na realidade contemporânea é através do pensamento complexo indiciado por Edgar Morin.

Morin (2006, p. 11) aponta que linearidade e simplificação podem não corresponder mais com a realidade dos dias de hoje. Dessa forma, se torna necessário "evitar a visão unidimensional, abstrata. [...] É preciso, antes de mais nada, tomar consciência da natureza e das consequências dos paradigmas que mutilam o conhecimento e desfiguram o real", para que a concepção criativa e os métodos projetuais se tornem mais interativos e respondam de forma mais eficiente à nova realidade da arte, do design e seus desafios.

Pensando em meios mais eficientes de se transmitir o conhecimento, bem como projetar e produzir artefatos para a sociedade, Morin (2001) propõe que, acima de tudo, essas ações tenham como ponto principal a própria condição humana e suas complexidades. É necessário situar o indivíduo em seu contexto local e global, entendendo as instâncias internas e externas que o rodeiam, para que assim seja possível caminhar rumo a uma sociedade mais humanizada. Posto isso, Morin propõe o "remembramento dos conhecimentos", rompendo as fronteiras entre áreas de conhecimento e construindo novos métodos capazes de fazer conexões recíprocas entre as partes e o todo.

Ao pensar no "remembramento dos conhecimentos" é possível observar um campo de diálogo entre diferentes formas de artes corporais - entre elas, o origami como um desdobramento manual - e o design enquanto processo projetual criativo. O estudo aqui apresentado pretende contribuir para a pesquisa dos projetos artísticos contemporâneos, analisando novos métodos e processos criativos que cada vez mais se estabelecem através do entrelaçamento com outras áreas de conhecimento. Dentre as inúmeras possibilidades de diálogo das artes com outros saberes, foram escolhidas para esse estudo os aspectos das dobras enquanto incorporadas ao corpo e ao origami.

\section{O CONTEMPORÂNEO E AS NOVAS POSSIBILIDADES CRIATIVAS: ESTÉTICA RELACIONAL}

Os artistas contemporâneos possuem fundamental importância nas novas possibilidades criativas. De acordo com Santaella (2003, p. 27): "Temos de prestar aten- 
ção no que os artistas estão fazendo. [...] São os artistas que têm nos colocado frente a frente com a face humana das tecnologias".

Quando se trata da questão estética, em especial a contemporânea, Bourriaud (2009) indica na arte relacional a principal forma de encarar o mundo ao nosso redor, de maneira mais verossímil. Há, em verdade, uma abertura às novas linguagens, experimentações e meta-ações que antes não eram possíveis, ou que não eram levadas ao seu verdadeiro mérito: "O que ontem seria considerado informe ou 'informal' já não o é mais. Quando a discussão estética evolui, o estatuto da forma evolui com ela e através dela" (Ibid., p. 30).

A arte relacional, segundo o mesmo, é criadora de modelos e não de representações. Em outras palavras, ela se insere no tecido social sem necessariamente se inspirar nele (Ibid., p. 24-25). Nesse sentido, Flusser (2007, p. 28-29.) reitera Bourriaud, com a única diferença que ele chama a representação de pensamento material e o modelo de pensamento formal. Desse modo, Flusser compara o modo de ver e projetar de antigamente com o de hoje: o artista deixa de apenas se inspirar no mundo e replicá-lo em diferentes mídias para começar a construí-lo de forma mais ativa:

Pode-se dizer que o modo predominante no período barroco era o material [...]. Hoje em dia, é o modo formal que prevalece [...]. Esses dois modos de ver e de pensar levam a duas maneiras distintas de projetar: a material e a formal. A material resulta em representações (por exemplo, as pinturas de animais nas paredes das cavernas). A formal, por sua vez, produz modelos (por exemplo, os projetos de canais de irrigação nas tábuas mesopotâmicas). (FLUSSER, 2007, p. 29-30).

Posto isso, tanto Bourriaud como Flusser estabelecem que o processo criativo transfere seus esforços da representação sólida e verídica do meio externo para meta -ações dentro deste meio, ou seja, os projetos atuais se inserem dentro da realidade de outras maneiras que não a representação ou pensamento material. Portanto, dentro do pensamento atual que constrói modelos, a forma se torna uma formação, ou uma discussão: a arte "se apresenta como uma duração a ser experimentada, como uma abertura para a discussão ilimitada." (BOURRIAUD, op. cit., p. 20-21).

As proposições artísticas, antes configuradas em objetos fechados, assinados por um estilo e por alguém, se tornam objetos sensíveis: são formas abrangentes de conexão paradigmática que encontram dinamicamente uma práxis artística com outras práxis não necessariamente artísticas (Ibid., p. 29-30). Dentro do contemporâneo, onde as incertezas mesclam-se com as mudanças, Flusser (op. cit., p. 58.) dá alguns indícios do homem inserido nessa era codificada: "A vida deixou de ser um drama e passou a ser um espetáculo. Não se trata mais de ações, e sim de sensações. O novo homem [...] quer vivenciar. Ele deseja experimentar, conhecer e, sobretudo, desfrutar".

Nesse sentido, nos encontramos em uma transição para novas linguagens e comunicações, segundo Santaella (2003, p. 156), onde o primeiro momento é das novas produções provocarem um grande impacto sobre os meios antigos e clássicos, e o segundo momento é quando essas novas formas são tomadas pelos artistas como objetos de experimentação. 
A quebra na linearidade projetual - característica própria do contemporâneo - faz com que haja um novo momento onde ocorre a convergência de projetos e produtos em processos, como afirma Argan (2005, p. 265): “O projeto é um projetar contínuo, é exercer sempre uma crítica sobre a existência, e supor qualquer coisa de diferente e evidentemente melhor". O projeto artístico é, então, um constante processar, ações sucessivas de valorização que vão se atualizando conforme o tempo, o ambiente, a cultura e as tecnologias envolvidas.

Cada vez mais, nota-se o esfacelamento de fronteiras e o entrelaçamento de áreas, culturas e conhecimentos. Esse conjunto de ações converte-se na mestiçagem, vasto conceito contemporâneo desenvolvido por Serres (1993). Outro conceito bastante explorado no decorrer desse estudo - e que dialoga intimamente com a mestiçagem - é a hibridização.

De acordo com Santaella (op. cit., p. 135): “Há muitas artes que são híbridas pela própria natureza. [...] Híbridas, neste contexto, significa linguagens e meios que se misturam, compondo um todo mesclado e interconectado de sistemas de signos".

Diante desse contexto de entrelaçamentos e misturas, nota-se que a convergência de pensamentos, ideias, atitudes e ações possibilitam a criação de novas linguagens e formas de comunicação. Através dessa multiplicidade, algumas delimitações tendem a desaparecer, levando consigo valores e conceitos fechados e abrindo espaço para pensamentos mais abertos e fluidos (Cf. NOJIMA; BRAIDA; MOURA, 2014, p. 74).

A mestiçagem da linguagem fica ainda mais evidente quando se leva em conta as tecnologias aliadas à cultura digital e à mobilidade, pois são elas que trazem à tona novas formas de linguagens independentes, como evidencia Serres:

Ninguém pode pensar a mudança, a não ser sobre misturas [...]. A rede de comunicação torna inútil a presença, não tem centro; torna obsoleta a vigilância [...]. $\mathrm{O}$ mundo da informação toma o lugar do mundo observado. [...] A mensagem torna-se o próprio objeto. (SERRES, 2001, p. 23-45).

Com a autossuficiência da mensagem/objeto, observa-se hoje a variedade e a complexidade da realidade contemporânea. Realidade tal que constantemente se torna assunto de diversos estudos e reflexões, levando em consideração os aspectos que permeiam a vida do ser humano, e buscando entender a complexidade do mesmo nos dias atuais. A partir desse pequeno panorama, são dadas as premissas pelas quais este estudo se recortará mais especificamente dentro do ramo da estética do corpo e do origami e como essas duas vertentes se conectam entre si e com o mundo contemporâneo.

\section{OS LABORATÓRIOS CRIATIVOS: O NOVO ARTESÃO E A NOVA MÁQUINA}

Na denominada era pós-industrial, ao mesmo tempo em que são resgatadas linguagens antigas - a do origami e a performance corporal entre elas -, transpõem-se essas linguagens ao que é codificado, sensível e virtual (do latim, virtus, potência. Cf. 
LÉVY, 1996). As dobras traduzidas para a linguagem corporal e para as dobraduras japonesas estão expandindo seus pilares de significação e atuação: elas deixam o plano das significações representativas para se tornarem ferramentas de raciocínio criativo em inúmeros projetos das mais diversas naturezas.

O potencial do origami e do corpo se torna mais evidente dentro do ambiente dos laboratórios experimentais criativos. Para melhor entendimento do que são esses laboratórios, citam-se aqui dois grandes laboratórios em âmbito internacional: o "Garagem Fab Lab", com uma de suas sedes no Brasil, e o estúdio "Mode Lab", nos Estados Unidos.

Ambos os laboratórios criativos atuam em equipes multidisciplinares compostas por designers, artistas, arquitetos, engenheiros, programadores, entre outros. $O$ diferencial desses laboratórios é que eles não se restringem a um grupo intelectual fechado: as principais ações do "Garagem Fab Lab" e do "Mode Lab" são as oficinas dinâmicas colaborativas, ou seja, buscam a interação criativa com o público em geral.

Essas interações coletivas, se antigamente eram consideradas informais, hoje apresentam potenciais de ação relevantes para o sistema de inovação formal, de acordo com Bourriaud (op. cit., p. 30):

O indivíduo, quando acredita que está olhando objetivamente, no final das contas está contemplando apenas o resultado de intermináveis transações com a subjetividade dos outros. [...] a forma só assume sua consistência (e adquire uma existência real) quando coloca em jogo interações humanas.

Bourriaud também afirma que, quando se trata dos novos processos criativos contemporâneos "o espaço em que se apresentam suas obras é o da interação, o da abertura que inaugura todo e qualquer diálogo", pois o que as obras de artes "produzem são espaços-tempos relacionais, experiências inter-humanas que tentam se libertar das restrições ideológicas da comunicação de massa" (Ibid., p. 62). Com Bourriaud fica clara a fundamentação da abertura ao público que os laboratórios criativos contemporâneos aplicam em seus modos de ação, criação e experimentação.

O "Garagem Fab Lab" (Figura 1) e o "Mode Lab" (Figura 2) criam espaços de trocas coletivas que englobam infinitas possibilidades criativas, gerando metodologias mais dinâmicas e abrangentes. Outro ponto metodológico a ser considerado é o esforço dos laboratórios em incorporar a atuação de ferramentas novas e antigas. Por ferramentas novas entendemos os softwares de modelagem em três dimensões, a manipulação física remota por microcontroladores eletrônicos, impressoras em 3D, máquinas de corte a laser, entre tantas outras tecnologias emergentes. Por ferramentas antigas entendemos o fazer manual, o "hand made", os "crafts" (ambas as terminologias designando objetos feitos de forma manufaturada, também chamados de produzidos pela "mão humana") e, por fim, a performance do corpo (com a dança e o teatro) e o contato com os usuários. 


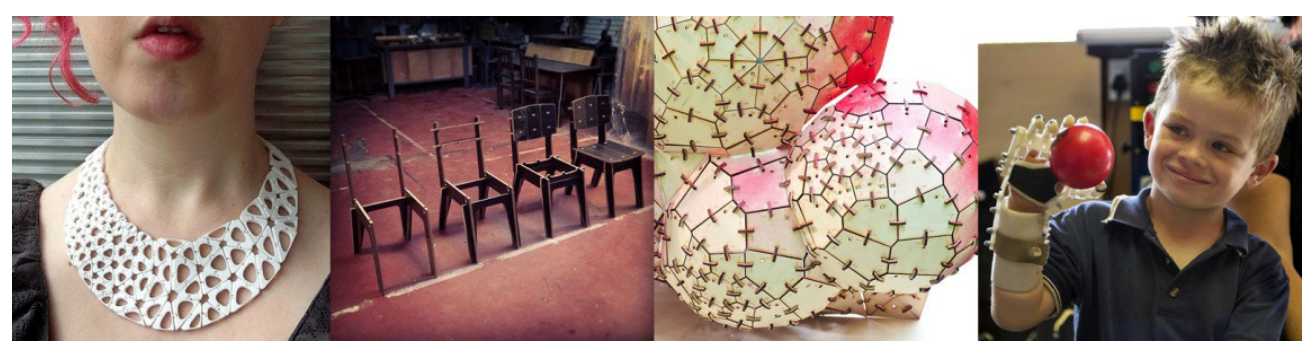

Figura 01: Garagem Fab Lab e os objetos criados por impressora 3D, fresadora e corte a laser. Os objetos vão desde a praticidade mais clara de um protótipo para substituir partes do corpo, passam pelo design de joias e interiores e vão até objetos mais subjetivos e conceituais, estudando formas, conexão e tecnologia. Fonte: GARAGEM Fab Lab. São Paulo: [s.n.], 2015. Disponível em: <http://www.garagemfablab.com/>. Acesso em: 26 jul. 2015.

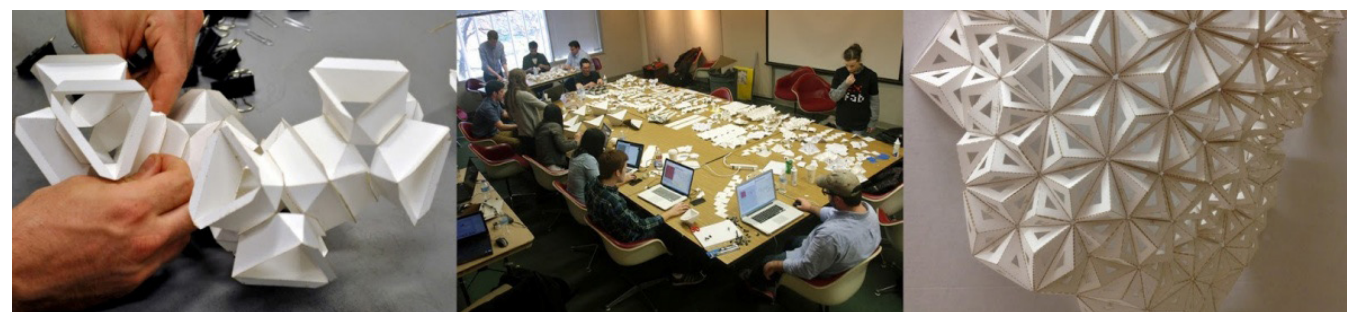

Figura 02: 0 estúdio Mode Lab concebe ideias em objetos misturando cortes a laser, mapeamento de dobras digitais e montagem física manual. O estúdio organiza frequentemente oficinas abertas ao público em geral. Fonte: AKOS, G. et al. Mode Lab Education. Nova lorque: [s.n.], 2015. Disponível em: <http://modelab.is/education/blog/news/>. Acesso em: 26 jul. 2015.

Uma das teorias de grande aceitação sobre o surgimento do design se encontra justamente dentro do contexto do "fazer humano", ou seja, artístico, em comunhão com o "fazer maquinário", em outras palavras, tecnologia:

Com o surgimento da indústria houve uma preocupação em aproximar as atividades do artesão e da máquina. [...] É na linha de frente artesão-máquina que surge a escola Bauhaus, fundada em 1919, na Alemanha, por Walter Gropius. (AZEVEDO, 1988, p. 14-19).

Hoje, em pleno século XXI, os laboratórios experimentais criativos aproximamse ainda mais dessa realidade homem + máquina de forma aprofundada, pois as tecnologias contemporâneas estão cada vez mais atreladas e impregnadas no dia-a-dia das pessoas. Hoje se pode dizer que a distância entre o artista e as máquinas tornouse praticamente inexistente, evidência que fica clara através dos trabalhos do "Garagem Fab Lab" e "Mode Lab".

Os dois laboratórios indicam claramente que há um movimento crescente de pequenos coletivos que trabalham por ideais das minorias, como indica Bourriaud (op. cit., p. 65) ser uma premissa cada vez mais presente nos dias de hoje: "[Há] uma mudança na sensibilidade coletiva: agora, joga-se o grupo contra a massa, a vizinhança contra a propaganda, o low tech contra o high tech, o tátil contra o visual".

\section{CORPO COMO PROCESSO CRIATIVO: FLEXIBILIDADE DE GÊ- NEROS, PERFORMANCE E A PRÁTICA DO NÓ/DOBRA}

A cultura contemporânea nos leva a uma convivência com excessos dos mais variados tipos: informação, imagens, sobreposição ou diluição do tempo e do espaço. Esses exageros abrem espaço para contradições, colocando as pessoas diante 
de um cenário instável e formado por diversos caminhos a serem seguidos. Assim, perde-se o referencial de ser imutável e completo e passa-se a lidar com uma nova identidade moldada às aparências físicas, que nesse momento, torna-se renovável e efêmera, atada a novos modelos e padrões de vida, de beleza e consumo.

Através dos Estudos Culturais, mais especificamente na visão do sociólogo Hall (2002), percebe-se que mudanças estruturais estão transformando as sociedades contemporâneas, deslocando o indivíduo de sua identidade fixa e imutável e abrindo espaço para novas identidades sociais. Segundo esse mesmo autor, a identidade hoje se tornou uma "celebração móvel", que é constantemente formada e transformada em relação aos sistemas culturais que nos rodeiam, sendo então "definida historicamente, e não biologicamente" (HALL, op. cit., p. 13). A cultura então influencia diretamente na formação da identidade de um indivíduo na sociedade. Neste sentido, Goellner (2012) analisa o corpo como algo produzido pela cultura e na cultura, afirmando que não são as semelhanças biológicas que definem um indivíduo, mas fundamentalmente os significados culturais inscritos em seu corpo.

A subjetividade do indivíduo se torna cada vez mais flutuante e desterritorializada, circunstâncias que são novamente traduzidas para o corpo, fazendo com que este passe a incorporar cada vez mais elementos estéticos para recriar, transmitir e afirmar sua identidade. Em meio a questionamentos e dúvidas sobre seu próprio "eu" e qual imagem transmitir ao mundo, a mídia ganha cada vez mais destaque, ditando padrões a serem seguidos. A mídia mostra tendências e estilos de vida capazes de influenciar padrões e comportamentos sociais, morais e estéticos através de imagens e discursos que são constantemente incorporados e compartilhados por grande parte da população. Dessa forma, é possível perceber que o corpo possui um papel fundamental no processo de criação e formação de identidade no contemporâneo.

Todos esses conflitos trazem à tona um organismo em contínua construção, um corpo que se dá a liberdade de mudar a qualquer momento, estando sempre aberto ao novo, se moldando e sendo moldado de acordo com a cultura na qual ele se insere. O corpo atua como um suporte para a construção social e de identidade, expondo a pluralidade do sujeito no mundo, e dessa maneira, se torne "o protagonista do processo de subjetivação e construção de uma imagem de si mesmo, que se substitui velozmente pelo descarte e substituição constantes e interruptas formas de ser e parecer" (CASTILHO; OLIVEIRA, 2008, p. 7). O corpo contemporâneo é reflexo de seu próprio tempo. Através do personagem Arlequim, Serres descreve o sujeito no mundo contemporâneo como um ser em transformação, que é definido e redefinido a todo instante:

Arlequim é hermafrodita, corpo mesclado, macho e mulher. Escândalo na sala, perturbada até as lágrimas. $\mathrm{O}$ andrógino nu mistura os gêneros sem que se possam distinguir as vizinhanças, lugares ou bordas onde terminam e começam os sexos: homem perdido na fêmea, mulher mesclada com o macho. (SERRES, 1993, p. 4).

A visão do mundo atual gira em torno dos gêneros que se fundem e se confundem em um só organismo, não sendo possível rotulá-los como masculino ou feminino, de fato, são corpos novos, dúbios, mestiços. Ao trazer essa metáfora para atu- 
alidade é possível encaixá-la em muitas situações onde o gênero binário (masculino ou feminino; homem ou mulher), assim como o sexo biológico já não são suficientes para definir a identidade pessoal de um indivíduo, que cada vez mais se torna fluida e híbrida (Cf. SALIH, 2012).

O termo gênero (do inglês: gender) surge nos anos 1970, cunhado inicialmente pela luta feminista e sendo gradativamente incorporado a outras diversas lutas e militâncias. Como aponta Meyer (2012), embora muitas dessas correntes possuíssem ideais distintos, o termo gênero foi utilizado como ponto em comum, com o intuito de questionar e desfazer a associação mútua do gênero ao sexo biológico. Meyer argumenta ainda que as "diferentes e desigualdades entre mulheres e homens eram social e culturalmente construídas e não biologicamente determinadas" (Ibid., p. 15), e assim, o uso de justificativas biológicas ou teológicas para as desigualdades passa a ser questionado.

A problematização sobre as noções de gênero são intensificadas e ressignificadas especialmente através das feministas pós-estruturalistas que passam a introduzir importantes mudanças epistemológicas nesse campo de estudo. Nas palavras de Meyer (2012, p. 16), essa nova abordagem se distancia de vertentes que colocam o corpo como uma entidade biológica universal para então teorizá-lo como um constructo sociocultural e linguístico, fruto de relações de poder:

\footnotetext{
Nesse contexto, o conceito de gênero passa a englobar todas as formas de construção social, cultural e linguísticas implicadas com os processos que diferenciam mulheres de homens [...]. O conceito de gênero privilegia, exatamente, o exame dos processos de construção dessas distinções - biológicas, comportamentais ou psíquicas - percebidas entre homens e mulheres. (Idem).
}

Butler (2015, p. 44) analisa o gênero como algo performativamente produzido, sendo construído através de "práticas reguladoras que geram identidades coerentes por via de uma matriz de normas de gênero coerentes", legitimando e conferindo inteligibilidade aos corpos sexuados. Bento (2006, p. 21), ancorada pelos estudos "queer", afirma não existir um corpo anterior à cultura, pois o mesmo é "fabricado" mediante preciosas tecnologias que garantem a inteligibilidade de gênero aos corpos sexuados (corpo-mulher e corpo-homem). Nesse sentido, Meyer (op. cit., p. 18) indica que a construção do gênero acontece por meio das mais diversas instituições, normas, leis, doutrinas, políticas e práticas sociais capazes de delimitar os conceitos de feminilidade e masculinidade dentro de uma cultura. Assim, ao pensar no sistema binário, atribui-se compulsoriamente o gênero ao sexo biológico, limitando a liberdade de escolha e orientação sexual entre ser homem e assumir uma postura masculina, ou ser mulher e assumir uma postura feminina. Posto isso, diante das complexas formas de identidade no contemporâneo, torna-se mais clara a necessidade de subverter o sistema binário de gênero, sendo este, um conceito extremamente reduzido para o mundo atual.

Hoje é possível encontrar mais espaço para se expressar e se afirmar através do corpo. $\mathrm{O}$ avanço de diferentes tecnologias aliadas à ciência têm ampliado cada vez mais as possibilidades estéticas, o que tornou possível atualmente a remodelagem de praticamente todas as partes do corpo humano- inclusive, do sexo, deixando ainda 
mais evidente o corpo como uma forma de ressignificação.

Na figura 03, é possível observar as possibilidades de construção corporal através da cartunista Laerte Coutinho, que começou sua transição de gênero há cerca de dez anos. Hoje, Laerte diz não se preocupar tanto em se definir como bissexual, transexual ou travesti. Em entrevista ao Portal IGay, a cartunista afirma que as questões que envolvem a transgeneridade vão muito além da mudança da genitália, elas abordam aspectos familiares, relações pessoais e profissionais (GIUSTI, 2014).

Posto isso, vale ressaltar que Laerte foi capaz de levantar uma importante discussão sobre a liberdade social, sexual e a orientação de gênero, questões cada vez mais discutidas nos dias de hoje.

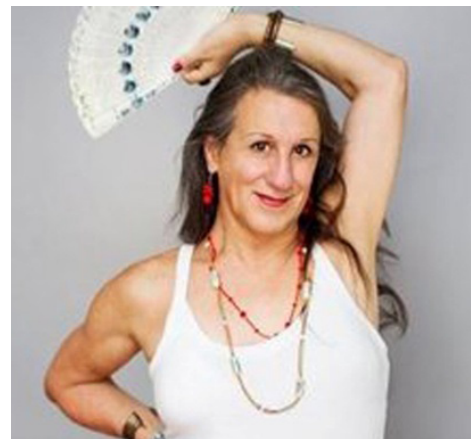

Figura 03: Laerte Coutinho, foto por André Giorgi. Uma das grandes cartunistas brasileiras viveu a maior parte da sua vida como homem. Hoje pôde assumir quem realmente ela é. Fonte: GIUSTI, I. Laerte: Gostaria de não ter renegado minha homossexualidade por 40 anos. São Paulo: [s.n.], 2014. Disponivel em: <http://igay.ig.com.br/2014-03-11/laerte-gostaria-de-nao-ter-renegado-minha-homossexualidade-por-40-anos. html>. Acesso em: 26 jul. 2015.

Os desdobramentos do corpo hoje vão além das questões de gênero e identidade. O corpo no contemporâneo passa a ser objeto de estudo e de discussão em qualquer veículo de comunicação e transmissão de conhecimento. Seu potencial desperta interesse em diferentes áreas, fazendo com que seja abordado em diferentes perspectivas. A função representativa do corpo é importante ao se analisar, por exemplo, os antigos rituais que deram origem ao teatro (no mundo ocidental), à dança e, atualmente adquiriram formas expressivas extremamente complexas que passam pela sua utilização como suporte (body art, tatuagem, piercing) e também pelo uso como principal elemento de produção de sentido artístico no teatro e na dança contemporâneos (GARDIN, 2008, p.75), ou ainda como identificação em sociedades prisionais, as quais utilizam tais elementos de forma subjetiva (CURIMBABA et al., 2015).

Na figura 04 temos a instalação do artista cubano Erik Ravello, onde é possível perceber o uso do corpo como o próprio objeto de experimentação e experiência, se tornando parte fundamental do exercício projetual e do processo criativo. O making of é incorporado como parte do projeto, deixando o corpo e a noção de dobra ainda mais em evidência. 


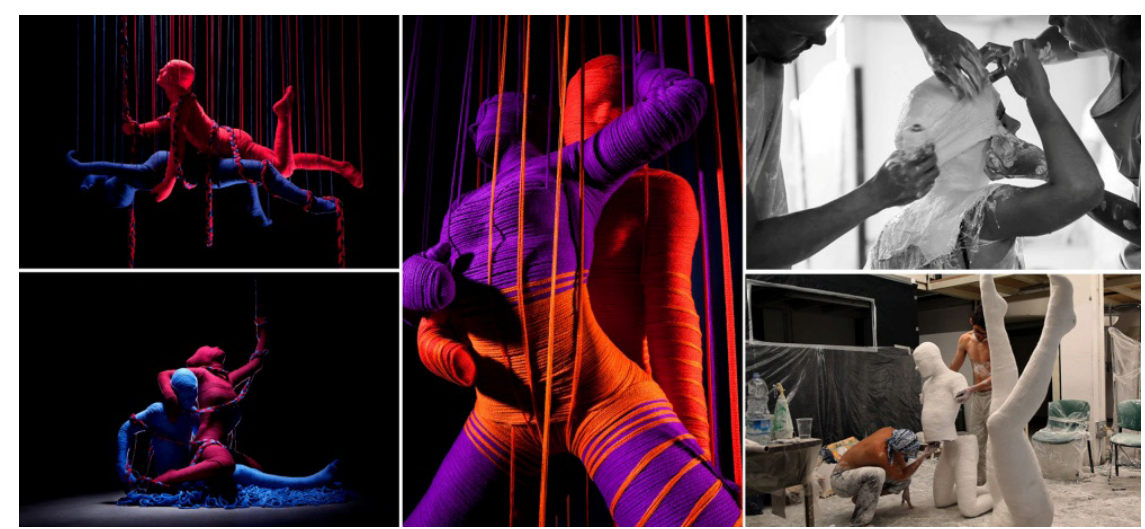

Figura 04: Instalação e Making Of Lana Sutra, realizado por Erik Ravello. O corpo paira sob a ótica das cores, formas e dobras, em busca de novas discussões estéticas através da performance corporal. Fonte: RAVELLO, E. Lana Sutra. [S.I.: s. n.], 2011. Disponível em: <http:// erikravelo.info/lanasutra/>. Acesso em: 26 jul. 2015.

A performance Lana Sutra mistura movimentos ensaiados e improvisados, a interação entre corpos e diferentes materiais, todos esses processos hibridizados em busca de uma estética contemporânea palpável tanto aos que executam as ações quanto aos que as assistem. Tal prática pode ser entendida como uma metodologia criativa descrita pelo filósofo Michel Serres como a prática do nó/dobra (2001, p. 74-75):

Onde e como introduzir um fio entre dois fios, por onde passar, por qual espaço? É preciso ir de dimensão a dimensão para compreender melhor. Onde e como introduzir uma folha entre duas páginas, por onde passar, por qual espaço? [...] É preciso imaginar dobraduras, invaginações, situações extraordinariamente complexas que generalizam a prática e a noção de nó em todas as dimensões imagináveis.

Na prática do nó, ou da dobra, Serres (Ibid.) conduz o princípio básico de conhecimento em gerar objetos complexos e pulsantes. Não são construções aleatórias nem mesmo com demasiada programação. Trata-se antes, de saber explorar e fazer do explorar a principal ferramenta para conceber ideias e objetos. Sendo assim, um dos raciocínios tangíveis ao artista é a dobra, pensamento vasto indicado por Deleuze (1991, p. 44): "As dobras estão na alma e só existem atualmente na alma. Isto já é verdadeiro no caso das 'ideias inatas': são puras virtualidades, puras potências, cujo ato acabado consiste em uma ação interior da alma".

No caso da Lana Sutra, a virtualidade da dobra encontra-se personificada através da experimentação, ou diálogo performático, envolvendo as dobras do corpo, as tramas em fios e a interação física coletiva. Portanto, se a dobra é um ato complexo que diz respeito ao interior da alma, o Lana Sutra é um dos meios estéticos que Erik Ravello encontrou para materializar e externalizar a dobra.

\section{ORIGAMI COMO PROCESSO: A PARTE COM O TODO E O SU- PORTE TÁTIL}

Depois de tomar conhecimento da dobra do corpo, entra-se agora na dobra incorporada às dobraduras japonesas. O origami era, inicialmente, uma arte ancestral do oriente que consistia em dobrar papéis e modelar diversos tipos de figuras representativas da natureza - como os animais, ou figuras abstratas - como as formas 
geométricas. Atualmente, o origami tem apresentado uma série de mudanças significativas em sua maneira de se expressar:

[...] o origami é, ao mesmo tempo, uma velha e nova arte. A sua nova fase é um tanto surpreendente. Afinal, a dobradura vem sendo uma forma de arte há cerca de quinze séculos. Ela é ancestral; não se esperava que 98 por cento da sua inovação surgisse nos últimos 2 por cento de existência desta forma de arte! (LANG, 2003, p. 3, tradução nossa).

Lang criou diversos modelos de origami próprios (embora sua formação acadêmica seja dentro da física) e passou a elencar e divulgar mundialmente a aplicação projetual do origami contemporâneo em diferentes áreas. Com a aparição de pesquisadores como Lang, a importância da trajetória atual do origami vem sendo amplamente evidenciada e cada vez mais estudada e aplicada. Isso se deve ao caráter mutável do origami, fazendo com que sua natureza em dobra permeie por diferentes áreas com naturalidade, não apenas dentro da arte, mas especialmente nas ciências e indústrias:

Reciprocamente, a arte do origami [...] está profundamente conectada com os mundos da matemática e ciência. [...] Na exploração, elucidação e descrição dessas leis matemáticas, os artistas modernos de origami têm encontrado caminhos que levam esta arte a alturas inimagináveis, e começam a desenvolver ferramentas computacionais que aumentam as capacidades do artista humano, percebendo mais plenamente, no fim de tudo, suas visões artísticas. Ao mesmo tempo, essas explorações matemáticas permitiram que o origami, ou mais amplamente falando, as estruturas em dobras, assumissem aplicações pragmáticas e trouxessem benefícios reais para o mundo. Estruturas dobradas com base em princípios do origami estão sendo aplicadas em voo espacial, eletrônicos de consumo, saúde e segurança, só para citar algumas das áreas onde origami faz uma aparição inesperada. (LANG, op. cit., tradução nossa).

Dentro dos muitos exemplos aplicados, fez-se aqui um recorte mais voltado para o corpo em comunhão com o origami. Um dos primeiros exemplos mais conhecidos trata-se do estilista Issey Miyake que, mesmo nos anos 90, já era evidenciado por autores como Azevedo (1994, p. 17) como precursor de toda uma linguagem própria inovadora: "Os japoneses muniram-se da paciência da cerimônia do chá e esperam a hora certa para mostrar que também sabem vestir-se e des-vestir-se: Issey Miyake é a prova disso".

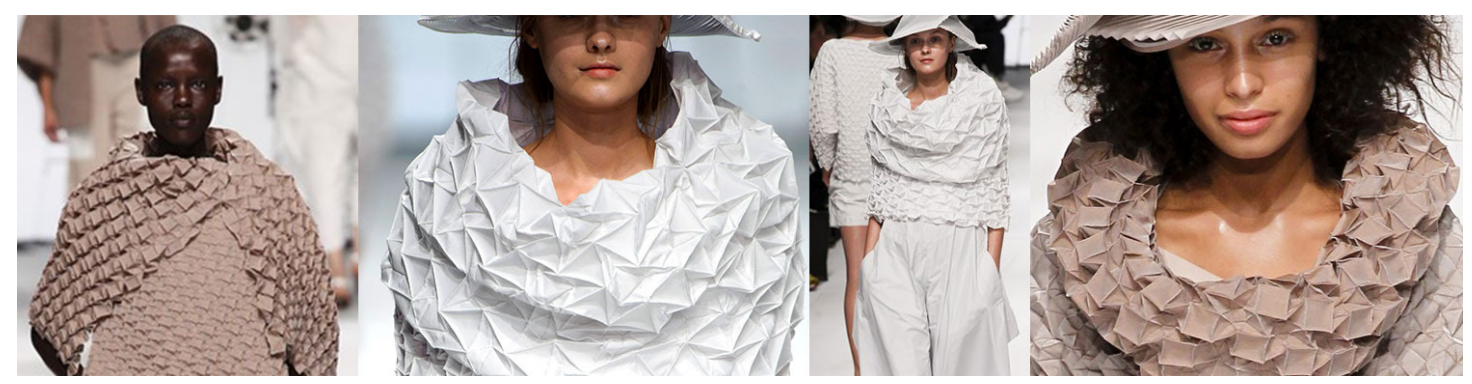

Figura 05: Na área de moda, a coleção de Primavera Verão 2015 do estilista Issey Miyake engloba em suas peças a linguagem de um ramo específico das dobraduras japonesas: o Origami Tessellation. Fonte: SPRING/SUMMER 2015 Ready to Wear Issey Miyake. Reino Unido: Vogue UK, 2014. Disponível em: <http://www.vogue.co.uk/fashion/spring-summer-2015/ready-to-wear/issey-miyake>. Acesso em: 27 jul. 2015. 
A última coleção lançada pelo mundialmente conhecido Issey Miyake traz mais uma das muitas referências ao origami que o estilista se propõe fazer em suas criações. As peças de primavera verão de Miyake, como vistas na figura 05, possuem diversas pequenas dobras que se repetem ao longo do tecido, fazendo uma combinação dinâmica entre as formas orgânicas da vestimenta como um todo e as formas geométricas das dobraduras nos detalhes. Essa relação entre o todo e as partes ilustra o princípio do holograma descrito por Morin (2006, p. 75):

\begin{abstract}
Num holograma físico, o menor ponto da imagem do holograma contém a quase totalidade da informação do objeto representado. [...] No mundo biológico, cada célula de nosso organismo contém a totalidade da informação genética deste organismo. A ideia do holograma vai além do reducionismo que só vê as partes e do holismo que só vê o todo. É um pouco a ideia formulada por Pascal: 'Não posso conceber o todo sem as partes e não posso conceber as partes sem o todo'.
\end{abstract}

O todo e as partes como estados de arte coexistentes e conectivos entre si são paradigmas claros dentro do raciocínio da dobra. As peças de Miyake mostram uma relação intrínseca entre o origami (a parte) com o corpo (o todo). O desfile de exibição das peças em si, muito comuns nas passarelas de moda no mundo inteiro, não deixa de ser uma performance corporal. $O$ trabalho de Miyake é um exemplo de como corpo e origami se juntam em prol da estética da dobra e do contemporâneo. Esse particular comportamento do origami contemporâneo não diz respeito somente ao "fazer" em dobra, mas a toda cultura que a práxis artística oriental abarca:

\footnotetext{
Podemos observar como surgem formas entre as mãos dos orientais, por exemplo, ideogramas escritos com pincel, flores de papel, ou simplesmente o modo como realizam o gesto da cerimônia do chá. Em todos esses casos não se trata de uma ideia imposta sobre algo amorfo; trata-se de fazer surgir de si mesmo e do mundo circundante uma forma que abarque ambos. [...] Se considerarmos a palavra estético em seu significado originário (isto é, no sentido de "experimentável", de "vivenciável"), podemos afirmar que o design no Oriente é puramente estético. (FLUSSER, 2007, p. 208-209).
}

Porém, o origami encontra-se hoje tão multifacetado nas diferentes culturas e países, que sua complexidade de ação artística e projetual não se devem mais especificamente ao Japão, mas ao mundo. Os próximos exemplos a seguir encontram-se no hemisfério ocidental que, embora não sejam os precursores do origami, certamente se apropriaram dessa linguagem com peculiar empenho.
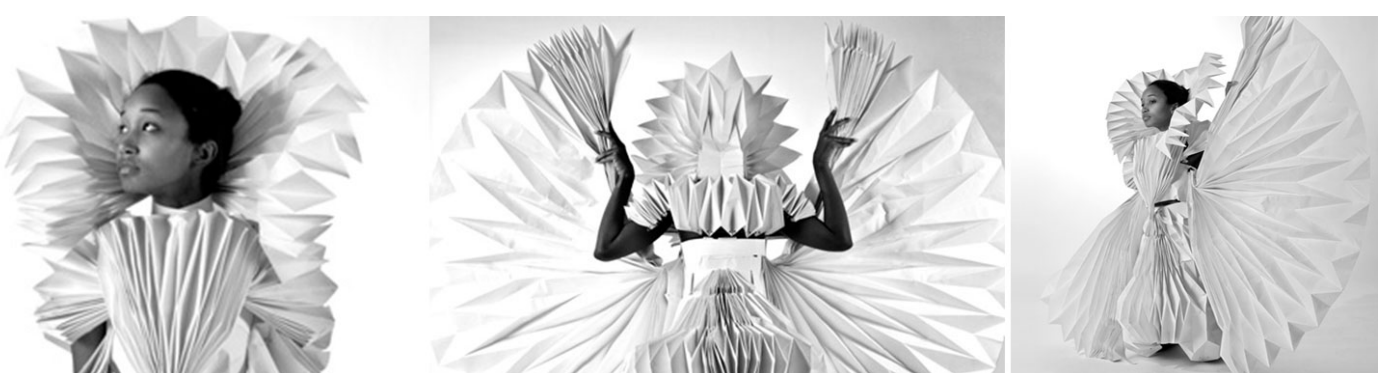

Figura 06: "Ecstatic Spaces", trabalho artístico da arquiteta Tara Keens Douglas. Fonte: ECSTATIC Spaces by Tara Keens Douglas. [S.I.: s. n.], 2012. Disponível em: <http://www.dezeen.com/2012/08/21/ecstatic-spaces-by-tara-keens-douglas/>. Acesso em: 27 jul. 2015. 
Para sua tese de mestrado em arquitetura na Universidade de Waterloo, no Canadá, Tara Keens Douglas criou o ensaio fotográfico performático "Ecstatic Spaces". As vestimentas criadas por ela foram feitas com dobras que distorcem temporariamente a natureza do corpo em quatro âmbitos operacionais: apropriação, exagero, submersão e sublimação. O trabalho de Douglas ilustra com clareza a natureza híbrida da vestimenta, do corpo e do tato descrita por Michel Serres (2001, p. 76):

$\mathrm{O}$ tecido pregueia-se, franze-se, dobra-se sobre si, mata-se à vontade. A pele se enruga, se adapta, reina entre os órgãos, contém os caminhos complexos que os ligam; mais que o meio dos órgãos dos sentidos, a pele mistura como uma paleta.

Em seu livro "Os cinco sentidos", Serres aponta no corpo e no tato uma importância estética a ser considerada. Quando o autor diz que a pele mistura como uma paleta, uma das interpretações possíveis está na indução de que o corpo também é um "pincel", ou seja, uma ferramenta para o artista, e o espaço e tempo seriam a sua "tela". Segundo o mesmo, as referências ocidentais dizem respeito mais à visão do que aos outros sentidos e essa tendência cultural culmina no cultivo a uma visão unilateral das coisas, portanto, não completa, especialmente no que diz respeito à prática criativa, que ele descreve como "suporte":

Antes de qualquer forma, antes da cor, do tom, é preciso tocar bem o suporte. [...] Antes de qualquer olhar, o grão da tela. O olho não pesa sobre o lugar; não imprime nada nele. [...] No começo, o tato: na origem, o suporte. [...] O olho, à distância, flana, passivo. Não há impressionismo sem uma força impressora, sem pressões do tato. (SERRES, 2001, p. 29-30).

Serres pontua a mudança de percepção em obras como de Pierre Bonnard: antes de objetivar a visão, que é passiva e distante, Bonnard busca o tato, o contato que imprime, que interfere fisicamente. O origami nasceu exatamente do contato tátil com o suporte, no caso o papel. Daí então sua natureza ser multidisciplinar, mutante, interativa com outras áreas, artísticas ou não.
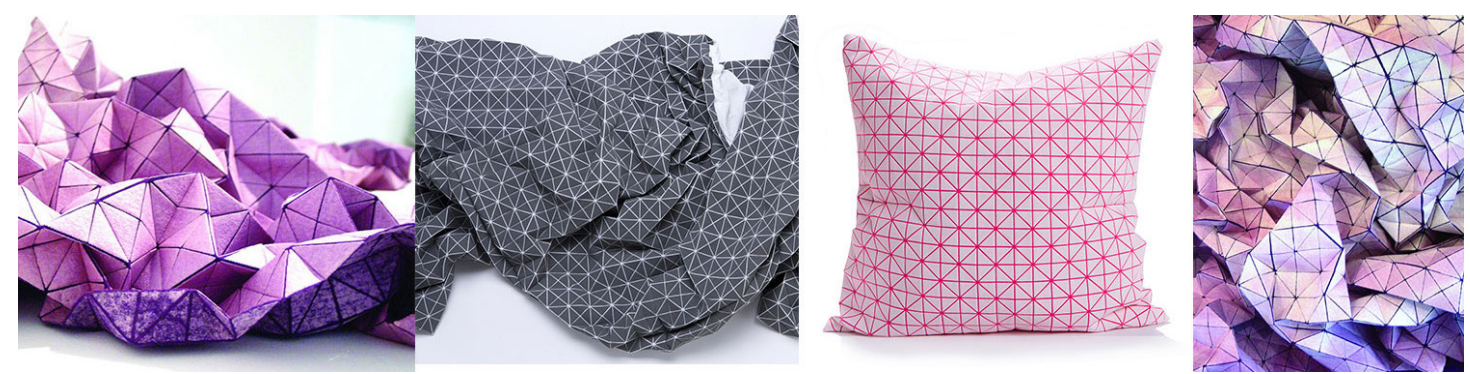

Figura 07: "Folding-A-part", a série de tecidos em 3D criados pela artista e designer Mika Barr. Fonte: MIKA Barr Studio. Israel: [s.n.], 2015. Disponível em: <http://www.mikabarr.com/>. Acesso em: 27 jul. 2015.

Sediado em Israel, o estúdio da artista e designer Mika Barr possui trabalhos em textura 3D que elencam dobras e geometria em tecidos. A mutabilidade desses tecidos tornaram os produtos de Barr versáteis e aplicáveis em diversas áreas do design de interiores, da moda e da arte. Tal como o origami, a série "Folding-a-part" utiliza a ferramenta paradigmática da dobra para transformar os tecidos, que estão em duas dimensões, para outros novos objetos em três dimensões. A composição faz com 
que o suporte varie desde uma peça mais abstrata, que trabalha as texturas, dobras e formas geométricas de forma mais livre e aberta, até um objeto funcional claro e direto como uma almofada ou um tapete.

Os exemplos acima buscam ilustrar melhor a nova interação que o origami tem composto com a inovação, criatividade e principalmente, com o mundo. Outra maneira de entender o porquê do caráter multidisciplinar do origami é um aprofundamento da questão dobra com o filósofo Deleuze. Diferentemente de Serres, que se ateve aos aspectos humanos, Deleuze (1991) construiu o conceito da dobra além do ato tátil/físico dos corpos. De acordo com o mesmo (op. cit., p. 16), a dobra compõe um raciocínio complexo que intermedia diversos tipos de naturezas e situações de nossa realidade como, por exemplo, no meio ambiente, onde a matéria como um todo se torna maleável, pois está sujeita a mudanças intermediadas pela dobra (que pode ser interpretada, neste caso, como ações do clima e da interação entre os elementos químicos):

Dobras de ventos, de águas, do fogo e da terra e dobras subterrâneas de filões na mina. Os dobramentos sólidos da "geografia natural" remetem, inicialmente, à ação do fogo e, depois, à ação das águas e dos ventos sobre a terra, um sistema de interações complexas. [...] A ciência da matéria tem como modelo o origami, diria o filósofo japonês, ou a arte de dobrar o papel (DELEUZE, op. cit., p. 18).

Ao dissecar o conceito de dobra, Deleuze aponta também para uma nova situação: a desdobra. Com a dobra, as coisas diminuem, com a desdobra, as coisas aumentam, e tais ações estão intrínsecas umas nas outras:

A desdobra. Certamente, a desdobra não é o contrário da dobra nem sua elisão, mas a continuação ou a extensão do seu ato, a condição de sua manifestação. Quando a dobra deixa de ser representada para tornar-se 'método', operação, ato, a desdobra vem a ser o resultado do ato que se expressa precisamente dessa maneira. (DELEUZE, op. cit., p. 60).

Tal método da dobra e desdobra é evidenciado nos estudos de Stewart, que grifa também a multidisciplinaridade do origami de modo menos abstrato e mais aplicado ao utilitarismo:

Economizar espaço é um imperativo no comércio, na engenharia e nas estruturas dos seres vivos. [...] A inspiração dos pesquisadores nesta área vem de duas fontes muito diferentes: "biomimética" - a tecnologia mimética de estruturas e processos biológicos-, e a arte ancestral japonesa do origami. Os resultados têm sido intrigantes e engenhosos, e já possuem aplicações em mapas, embalagens de comida, recipientes de bebidas dobráveis, air-bags de carros e antenas de naves espaciais. (STEWART, 2007, p. 419, tradução nossa).

Os objetos em dobras são projetados de maneira a lhes conferir uma mutabilidade de compactação e expansão coexistentes. Tal combinação, como confirma Stewart acima, fez com que o origami se aproximasse ainda mais dos processos biológicos naturais e, com isso, adquirisse dinamismo de adaptação ao seu meio e possibilidades de aplicações em inúmeras áreas. À luz dessas análises, entende-se que a prática das dobraduras pode culminar não apenas em um raciocínio fechado ao exer- 
cício estético ou artesanal, mas em benefícios diretos ou indiretos para a sociedade.

\section{Estudos de caso: Dobras em corpo, dobras em papel}

Esse capítulo falará mais especificamente de projetos que contenham o corpo e o origami em conexão. O primeiro estudo de caso é o trabalho do estúdio Peripetie, mais especificamente o editorial desenvolvido na revista Hunger:

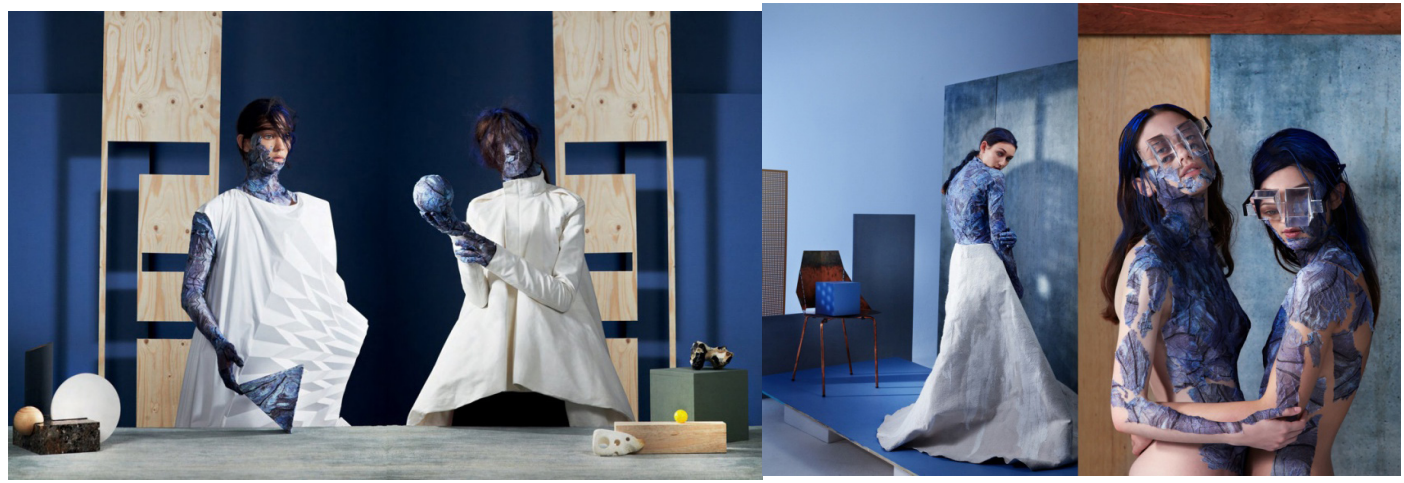

Figura 08 e 09: Corpo e origami compõem a fotografia conceitual, uma mistura de dobras, formas e cores. Fonte: STUDIO Peripetie. Londres: [s.n.], 2015. Disponivel em: <http://studio-peripetie.com/hunger-magazine>. Acesso em: 27 jul. 2015.

O ensaio fotográfico acima é produto de um editorial de moda. Pairando livremente sob a profundidade do conceito dobra em corpo e dobra em papel, esse editorial é um claro exemplo da constatação contemporânea da mistura de conceitos entre pessoas, ambientes e objetos estão cada vez mais presentes no cerne da realidade. Tal como Bourriaud descreve, chegamos a um ambiente em que fica difícil separar a arte e o design, a função e a reflexão, o comum e o anacrônico:

Observando as práticas artísticas contemporâneas, deveríamos falar mais em 'formações' do que em 'formas': ao contrário de um objeto fechado em si mesmo graças a um estilo e a uma assinatura, a arte mostra que só existe forma no encontro fortuito, na relação dinâmica de uma proposição artística com outras formações, artísticas ou não. (BOURRIAUD, op. cit., p. 29-30).

Outro projeto que envolve corpo e origami é "Veasyble", uma série de produtos conceituais criados pelo grupo Gaia.

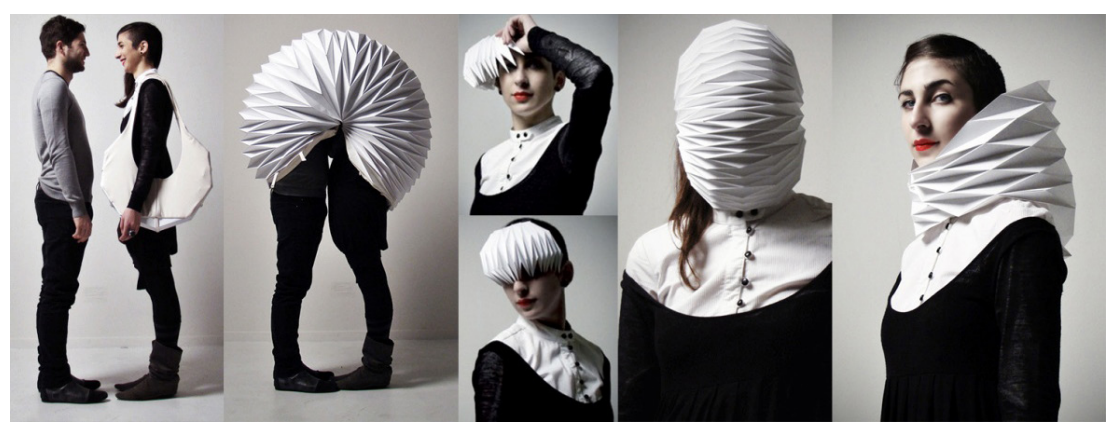

Figura 10: A série de produtos conceituais "Veasyble", desenvolvido pelo grupo Gaia, é um conjunto de peças em origami que envolve os corpos, buscando um diálogo entre corpo e dobras. Fonte: BACCI, A. et al. Veasyble: Unfold an beautiful intimacy. Itália: [s.n.], 2009. Disponível em: <http://www.veasyble.com/index.html>. Acesso em: 27 jul. 2015. 
O grupo Gaia é composto por quatro mulheres, que possuem especialidade em ilustração, performance corporal e música: Gloria Pizzilli, Arianna Petrakis, Ilaria Pacini e Adele Bacci. Percebe-se em "Veasyble" que há uma linha muito tênue e confusa entre o que podem ser objetos de arte, design de produtos e design de moda. Buscando a individualidade, reclusão, intimidade, omissão de rostos e corpos, as dobras nesse caso intermediam os objetos e os usuários de maneira inusitada e intrigante.

Através do grupo Gaia é possível perceber que o tátil conecta os origamis à performance corporal, possibilitando a "mudança na sensibilidade coletiva" citada por Bourriaud no item 3 desse estudo. Nesse sentido, ao analisar a arte relacional, Bourriaud descreve que a mesma "não é o revival de nenhum movimento, o retorno a nenhum estilo; ela nasce da observação do presente e de uma reflexão sobre o destino da atividade artística." (op. cit., p. 61).

Como outro exemplo de conexão entre corpo e origami, cita-se o estúdio PetraStorrs que, em 2009, criou um projeto capaz de mesclar conceitos de arte, moda, música e design em uma instalação destinada ao V\&A (Victoria and Albert Museum, em Londres). PetraStorrs, com sede em Londres, possui um trabalho que abrange desde o desenho inicial até a construção final de figurinos, adereços, cenários para fotografia, cinema e teatro, sempre buscando inovar e testar elementos inusitados.

A instalação se deu por meio de dançarinos em movimentos sincronizados e em sintonia com os figurinos que também se mexiam. Os figurinos foram confeccionados por Hannah Marshall, Louise Gray, William Tempest e Dean Quinn. Na figura 11 é possível perceber o diálogo entre corpo, figurino, e cenografia. As estruturas dinâmicas se relacionam diretamente com o origami ao mesmo tempo em que se fundem ao corpo e a instalação como um todo.

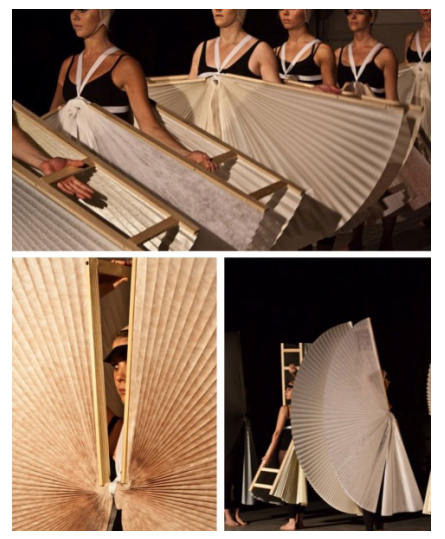

Figura 11: Instalação projetada pelo estúdio PetraStorrs, cuja interação se baseia na mescla dos elementos que contém preceitos da arte, moda, música e design, tudo intermediado por estruturas em origami. Fonte: V\&A Raphael Gallery Fashion Instillation by Petra Storrs. Londres: [s.n.], 2015. Disponível em: <http://petrastorrs.com/projects/va-installation/>. Acesso em: 26 jul. 2015.

Por fim, outro projeto que merece destaque é "A Hora do Brasil", do designer e estilista Jum Nakao, em parceria com o SENAC. O projeto, realizado em 2012, aconteceu na 13ạ edição do Dragão Fashion Brasil. Durante o evento, o estilista inaugurou o projeto Indústria Criativa, que se baseou na criação de uma coleção com 22 peças de moda inéditas. Para o desenvolvimento do projeto foram selecionados dez estudantes de moda que, por meio da ajuda de professores e artesãos, desenvolveram as peças com técnicas de rendaria, selaria, xilografia e gravura. O resultado do projeto foi apresentado no último dia do evento na forma de um desfile (VOGUE, 2012). 


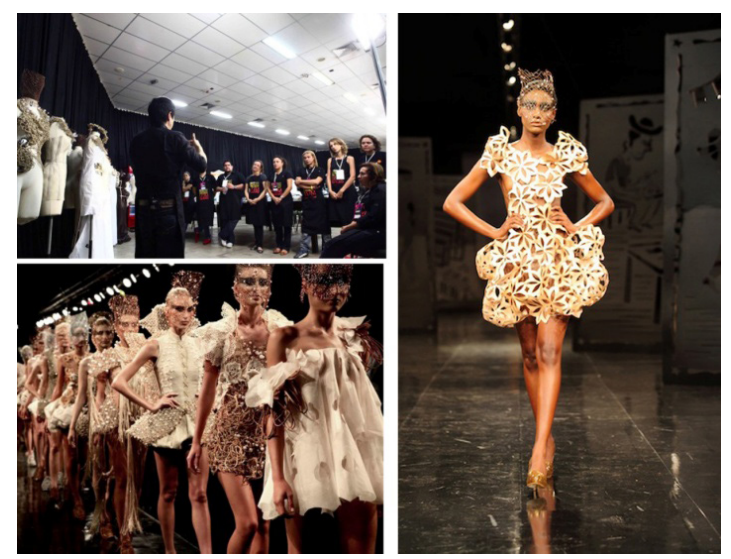

Figura 12: Projeto Indústria Criativa - "A Hora do Brasil" do estilista e designer Jum Nakao. Todo o processo de produção foi desenvolvido em um reality show de 4 dias, durante o evento Dragão Fashion Brasil, em 2012. Fonte: NAKAO, J. A hora do Brasil. Fortaleza: [s.n.], 2012. Disponível em: <http://www.jumnakao.com/portfolios/reality-project-a-hora-do-brasil/>. Acesso em: 31 jul. 2015.

O projeto dialoga intimamente com as novas formas de se pensar o fazer projetual dentro do design contemporâneo: a união de técnicas tradicionais e artesanais com a tecnologia somadas às diferentes áreas do conhecimento que tornou possível novos caminhos criativos para dialogar com a realidade contemporânea. O projeto de Jum Nakao evidencia o processo de produção (ou making of) e a relação do corpo com o figurino, um diálogo que acontece através de inúmeras dobras, formatos e cores. O corpo é parte ativa do processo de criação, é o espaço a ser ocupado, a ser explorado. O origami é a linguagem que permeia o corpo e, juntos, constroem novas possibilidades para o design.

Nesses estudos de caso, buscou-se o significado contemporâneo do corpo e do origami enquanto partes ativas do processo de criação. Percebe-se que tais projetos artísticos se desenrolam em dois momentos: o primeiro instante, em que o corpo desempenha o papel de espaço a ser ocupado, explorado; e o segundo instante, em que o origami se hibridiza como parte da linguagem desse novo corpo.

\section{CONSIDERAÇÕES FINAIS}

No presente artigo, buscou-se analisar o repertório geral dos conceitos e projetos que envolvem as linguagens do corpo e do origami em paradigmas mais condizentes com a nova realidade atual. Apontou-se a interação do design e das artes com o mundo contemporâneo, e como seus pilares de atuação estão cada vez mais focados em conceitos híbridos, como os projetos miscigenados e a criatividade multifacetada (abrangendo diversas áreas do conhecimento). Foi pontuada a importância dos laboratórios criativos, suas atuações na sociedade e a aglutinação de diferentes tecnologias, fomentando novas metodologias e formas de pensar e executar. Depois, foram analisados diversos aspectos específicos no que tange às tradições e mudanças do conceito corpo e do conceito origami de forma mais teórica. Ficou claro então que ambos os aspectos de corpo e origami, apesar de suas trajetórias singulares, se encontraram infalivelmente dentro dos novos aspectos da realidade contemporânea por possuírem uma forma inata de práxis mutável, adaptável. 
Por fim, foram apontados alguns projetos que utilizam a linguagem das dobras em suas metas de ação criativa, mais especificamente dentro da performance corporal e da aplicação de origamis atrelados aos corpos. A partir dos dados estudados, foi possível perceber que a ideia de se trabalhar com dobras traz possibilidades infinitas, indo desde a exploração do papel até o uso do próprio corpo como fontes do processo criativo.

Ao analisar as possibilidades criativas pelo viés da dobra, percebe-se um corpo que se redesenha, se reconstrói, utilizando tanto artefatos orgânicos como também incorporando elementos novos. O corpo e origami unem-se para trazer hoje o que há de mais sublime e inovador tanto para os artistas e designers como para a sociedade como um todo.

\section{Referências Bibliográficas}

AKOS, G. et al. Mode Lab Education. Nova lorque: [s.n.], 2015. Disponível em: <http:// modelab.is/education/blog/news/>. Acesso em: 26 jul. 2015.

ARGAN, G. C. História da arte como história da cidade (trad. Pier Luigi Cabra). 5. ed. São Paulo: Martins Fontes, 2005.

AZEVEDO, W. O que é Design. São Paulo: Brasiliense, Col. Primeiros Passos. 1988. Os signos do design. São Paulo: Global, Col. Contato Imediato, 1994.

BACCl, A. et al. Veasyble: Unfold an beautiful intimacy. Itália: [s.n.], 2009. Disponível em: <http://www.veasyble.com/index.html>. Acesso em: 27 jul. 2015.

BENTO, B. A reinvenção do corpo: sexualidade e gênero na experiência transexual. Rio de Janeiro: Garamond, 2006.

BOURRIAUD, N. Estética relacional (trad. Denise Bottmann). São Paulo: Martins Editora, 2009.

BUTLER, J. Problemas de gênero: feminismo e subversão da identidade (trad. Renato Aguiar). 8.ed. Rio de Janeiro: Civilização Brasileira, 2015.

CASTILHO, K. OLIVEIRA, A. C. Corpo e moda: por uma compreensão do contemporâneo. São Paulo: Estação das Letras e Cores, 2008.

CURIMBABA, R. G. et al. DNA Prisional: identidade à flor da pele. In: Actas del VIII Congreso Internacional de Diseño de La Habana. Habana: Instituto Superior de Diseño, 2015. 
DELEUZE, G. A Dobra: Leibniz e o barroco (trad. Luiz B. T. Orlandi). Campinas: Papirus, 1991.

ECSTATIC Spaces by Tara Keens Douglas. [S.l.: s. n.], 2012. Disponível em: <http:// www.dezeen.com/2012/08/21/ecstatic-spaces-by-tara-keens-douglas/>. Acesso em: 27 jul. 2015.

FLUSSER, V. O mundo codificado: Por uma filosofia do design e da comunicação (trad. Raquel Abi-Sâmara). São Paulo: Cosac Naify, 2007.

GARAGEM Fab Lab. São Paulo: [s.n.], 2015. Disponível em: <http://www.garagemfablab.com/>. Acesso em: 26 jul. 2015.

GARDIN, C. O corpo mídia: modos e moda. In: OLIVEIRA, Ana Claudia; CASTILHO, Kathia (Orgs). Corpo e moda: por uma compreensão do contemporâneo. Barueri: Estação das Letras e Cores, 2008. p.75-84.

GIUSTI, I. Laerte: "Gostaria de não ter renegado minha homossexualidade por 40 anos". São Paulo, [s.n.], 2014. Disponível em: <http://igay.ig.com.br/2014-03-11/laerte-gostaria-de-nao-ter-renegado-minha-homossexualidade-por-40-anos.html>. Acesso em: 31 jul. 2015.

GOELLNER, V. S. Currículo, gênero e sexualidade: o "normal", o "diferente" e o "excêntrico". In: LOURO, G. L. FELIPE, J. GOELLNER, S. V. (Org.). Corpo, gênero e sexualidade: um debate contemporâneo na educação. Petrópolis: Editora Vozes, 2012. p. 28-40.

HALL, S. A identidade Cultural na Pós-Modernidade (trad. Tomaz Tadeu da Silva e Guacira Lopes Louro). Rio de Janeiro: DP \& A Editora, 2002.

LANG, R. J. Origami Design Secrets: Mathematical Methods for an Ancient Art. 2. ed. Massachusetts: A K Peters, 2003.

LÉVY, P. O que é o virtual? (trad. Paulo Neves). São Paulo: Editora 34, Col. Trans, 1999.

MEYER, D. E. Gênero e educação: teoria e política. In: LOURO, G. L., FELIPE, J. GOELLNER, S. V. (Org.). Corpo, gênero e sexualidade. 8. ed. Rio de Janeiro: Vozes, 2012. p. 09-27.

MIKA Barr Studio. Israel: [s.n.], 2015. Disponível em: <http://www.mikabarr.com/>. Acesso em: 27 jul. 2015.

MORIN, E. Introdução ao pensamento complexo (trad. Eliane Lisboa). Porto Alegre: Sulina, 2006. 
Os sete saberes necessários à educação do futuro. (trad. Catarina Eleonora F. Da Silva e Jeanne Sawaya). 3. Ed. São Paulo: Cortez, 2001.

MOURA, M. Introdução. In: Design Brasileiro contemporâneo: reflexões. São Paulo: Estação das Letras e das Cores, 2014, p.11-34.

Atualidades da Pesquisa em Design e Moda no Brasil. dObra[s], São Paulo, n. 13, p. 24-35, abr. 2013.

NAKAO, J. A hora do Brasil. Fortaleza: [s.n.], 2012. Disponível em: <http://www.jumnakao.com/portfolios/reality-project-a-hora-do-brasil/>. Acesso em: 31 jul. 2015.

NOJIMA, V. L.; BRAIDA, F.; MOURA, M. A contemporaneidade híbrida nas Artes e no Design. In: MOURA, Mônica (Org). Design Brasileiro contemporâneo: reflexões. São Paulo: Estação das Letras e Cores, 2014. p. 69-92.

RAVELLO, E. LanaSutra. [S.l.: s. n.], 2011. Disponível em: <http://erikravelo.info/lanasutra/>. Acesso em: 26 jul. 2015.

SALIH, S. Judith Butler e a Teoria Queer (trad. Guacira Lopes Louro). Belo Horizonte: Autêntica, 2012.

SANTAELLA, L. Culturas e artes do pós-humano: da cultura das mídias à cibercultura. São Paulo: Paulus, 2003.

SERRES, M. Os cinco sentidos: Filosofia dos corpos misturados 1 (trad. Eloá Jacobina). Rio de Janeiro: Bertrand Brasil, 2001.

1993.

Filosofia mestiça (trad. Maria I. D. Estrada). Rio de Janeiro: Nova Fronteira,

SPRING/SUMMER 2015 Ready to Wear Issey Miyake. Reino Unido: Vogue UK, 2014. Disponível em: <http://www.vogue.co.uk/fashion/spring-summer-2015/ready-to -wear/issey-miyake>. Acesso em: 27 jul. 2015.

STUDIO Peripetie. Londres: [s.n.], 2015. Disponível em: <http://studio-peripetie.com/ hunger-magazine>. Acesso em: 27 jul. 2015.

STEWART, I. Some assembly needed. Nature, Londres, v. 448, p. 419-419, jul. 2007.

V\&A Raphael Gallery Fashion Instillation by Petra Storrs. Londres: [s.n.], 2015. <http:// petrastorrs.com/projects/va-installation/>. Acesso em: 26 jul. 2015. 
VOGUE Brasil. Dragão Fashion: estilista Jum Nakao é destaque com reality show criativo. [S.I.]: Vogue, 2012. Disponível em: <http://revista.vogue.globo.com/moda/ news/dragao-fashion-estilista-jum-nakao-e-destaque-com-reality-show-criativo/>. Acesso em: 31 jul. 2015

\section{Autores}

\section{Samanta Aline Teixeira}

Mestranda na Pós Graduação em Design, Planejamento de Produto, pela UNESP Universidade Estadual Paulista "Júlio de Mesquita Filho", Brasil - laranjasat@gmail.com

\section{Caroline Apolinário Gomes}

Mestranda na Pós Graduação em Design, Planejamento de Produto, pela UNESP

Universidade Estadual Paulista "Júlio de Mesquita Filho", Brasil

caroline.agomes@gmail.com

\section{Luis Carlos Paschoarelli}

Docente em Design Ergonômico pela Universidade Estadual Paulista "Júlio de Mesquita Filho", Brasil - paschoarelli@faac.unesp.br

\section{Milton Koji Nakata}

professor assistente doutor da Universidade Estadual Paulista Júlio de Mesquita FiIho, Brasil - miltonafaac.unesp.br

\section{Monica Moura}

Professora Assistente Doutora no Departamento de Design, Professora Permanente e Orientadora Credenciada no Programa de Pós Graduação em Design da Faculdade de Arquitetura, Artes e Comunicação - FAAC, Brasil - monicamoura@afaac.unesp.br 